\title{
Determination of Plastic Hinge Length for RC Beams Designed with Different Failure Modes under Static Load
}

\begin{abstract}
Y. SÜMER*
Department of Civil Engineering, Technology Faculty, Sakarya University, 54187 Sakarya, Turkey

Inelastic deformation without substantial loss of strength can lead to the dissipation of seismic energy in reinforced concrete structures during the earthquakes. Inelastic deformations are concentrated in specific areas within the structure, so called plastic hinge zones, and they are designed to redistribute the plastic moments. Dynamic response of the entire structure relies on these specific areas. Therefore, modeling them as close to its real location value within the structural element plays an important role especially in numerical analysis. The behavior and location of plastic hinge of reinforced concrete elements has been studied by conducting experiments. More research still need to be done by considering different parameters due to the high complexity engaged in the behavior. This study involves parametric study to determine the plastic hinge length of reinforced concrete beams using experimentally verified nonlinear finite element approach. Different failure behavior of reinforced concrete beams is selected as the parameter in the numerical analysis. Different failure modes are achieved with three different steel reinforcement ratio and with three different shear span ratio defining failure by means of ductility and slenderness, respectively. Results proved that both slenderness and the ratio of tensile reinforcement has effect on the plastic hinge length. Existing conclusions in the literature determine the plastic hinge length shorter than that found from numerical modelling. Thus, existing expressions approach to the energy dissipation phenomenon more conservatively.
\end{abstract}

DOI: 10.12693/APhysPolA.135.955

PACS/topics: reinforced concrete beams, plastic hinge length, finite element analysis, failure modes

\section{Introduction}

Yielding of reinforcement and crushing of concrete can be seen over a finite region known as plastic hinge length where the critical moment is present in structural elements. Plastic hinge region of reinforced concrete (RC) flexural members is a critical zone need to be given intensive care to prevent failure of structural members from extreme events such as earthquakes. There is no adequate determination of plastic hinge length of concrete structural elements. However, the length of plastic hinge region, $L_{p}$, is defined as the length over which the longitudinal reinforcement bucles under [1]. The performance of a plastic hinge is crucial to the load carrying and deformation capacities of flexural members of structures. The accuracy of the results obtained from nonlinear analysis is also directly related to the hinge definitions of the structure. Thus, plastic hinge length of RC members has been an interesting and complicated subject for researchers. There are no definitive theoretical formulations to calculate plastic hinge length in the literature. Present calculations are based on empirical equations observed from tests [2-6]. Park and Paulay [7] found that plastic hinge length of beams under monotonic loading is affected by concrete compressive strength, concrete ultimate strain, shear-span to depth ratio, and effective depth of section.

*e-mail: ysumer@sakarya.edu.tr
Mechanical properties of steel also affect $L_{p}$. Beeby studied the effects of the ratio of ultimate strength to yield strength of longitudinal reinforcement, $f_{u} / f_{y}$, and the ultimate strain, $\varepsilon_{u}$ on plastic hinge length [8]. Several expressions have been proposed for determining the equivalent plastic hinge length of beams and columns; some of these expression are summarized as follows:

- Corley [2]

$$
L_{p}=0.5 d+0.2 \sqrt{d}\left(\frac{z}{d}\right)
$$

- Mattock [3]

$$
L_{p}=0.5 d+0.05 z
$$

- Paulay [7] and Priestley [4]

$$
L_{p}=0.08 z+0.022 d_{b} f_{y} \geq 0.044 d_{b} f_{y}
$$

- Panagiotakos and Fardis [5]

$$
L_{p}=0.18 z+0.021 d_{b} f_{y}
$$

- FEMA 356 [6]

$$
L_{p}=0.5 d
$$

In these equations, $L_{p}$ is the plastic hinge length, $d$ is effective depth of the beam, $z$ is the critical distance from the critical section to the point of counterflexure, and $f_{y}$ and $d_{b}$ are the expected yield strength and the diameter of longitudinal reinforcement, respectively. There are some recent studies, which defines $L_{p}$ for columns [9-12]. Since the axial load level is included in those expression they are not considered here in this study. Limit state failure in flexure is achieved when the permanent increase in the external load reaches the capacity limit of the beam. If the designer picks out the project of 
the beam to allow concrete and steel reach their capacity prior to failure, both materials will fail simultaneously at the limit state. Moreover, compression failure of concrete before the tension failure of steel should be avoided to assure an adequate rotation capacity at limit state. Strain of tension reinforcement will be the determinant variable that defines the type of failure; tension controlled (ductile type of failure), compression controlled (brittle type of failure) and intermediate. This behavior according to ACI 318-14 is illustrated in Fig. 1a [13].
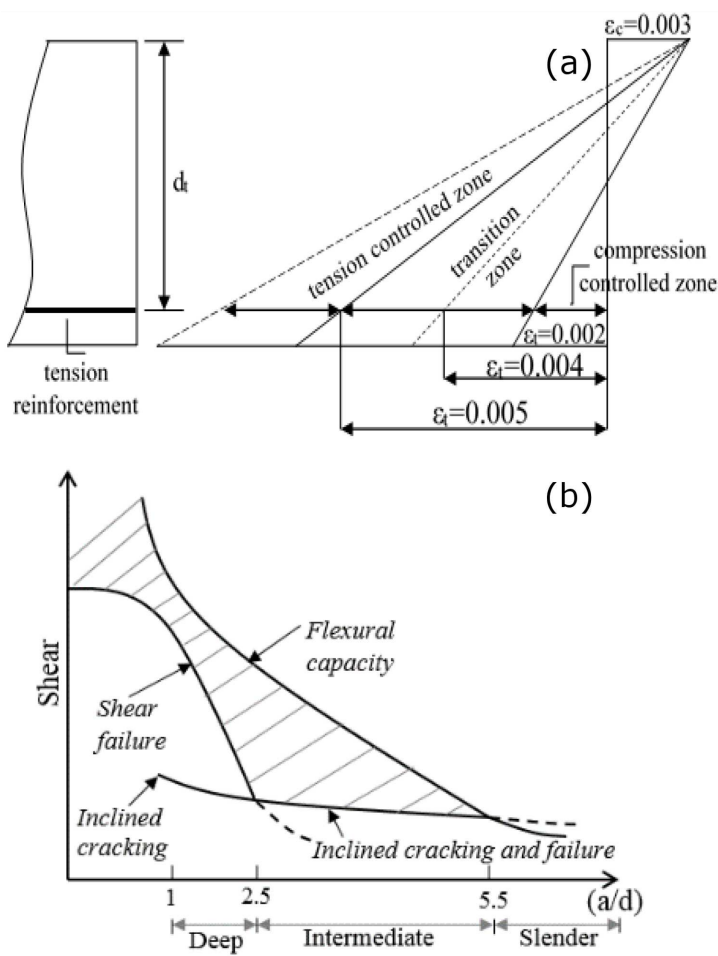

Fig. 1. (a) failure type of beams regarding to tensile strain of reinforcement; (b) determination of beam slenderness.

The behavior of beam is also determined by the slenderness of the beam in Fig. 1b [14]. Slenderness of RC beam is defined as the ratio of its shear span $(a)$ to its depth $(d)$. Deep beam with $a / d$ from 1 to 2.5 will form few small cracks at mid-span but after the redistribution of internal forces bond failure between the tension reinforcement and surrounding concrete at support region follows. This is also known as shear compression failure. Intermediate beam with $a / d$ from 2.5 to 5.5 will fail at the inclined cracking load. Slender beam with $a / d$ greater than about 5.5 will fail in flexure prior to the formation of inclined cracks giving sufficient warning of the collapse of the beam.

In this paper, determination of $L_{p}$ considering yielding zone of tension reinforcement is investigated for beams designed to achieve different types of failures. Verified nonlinear finite element approach is employed in the research to avoid the extensive testing of the specimens and minimize time and cost of experiments. With the verified numerical model, the breadth of reinforcement yielding zone, where the plastic hinge length is expected, was studied for RC beams with various failure modes.

\section{Preparation of numerical model}

In scientific studies finite element analysis has been widely used especially in civil engineering applications from steel structure analysis to RC analysis [15, 16]. Through in this study, ABAQUS was employed to simulate experimental testing as nonlinear finite element software package. Numerical model is verified with existing experimental data obtained from literature especially for load-deflection relation and axial force distribution of tensile steel reinforcement. The latter verification is more important since determination of $L_{p}$ in this study is made according to the yielding zone of tensile steel. Sensitivity of the numerical model to mesh density, dilation angle and fracture energy of concrete is also investigated.

Numerical model of simply supported beam under four-point loading was selected for verification purpose. Shear dominant members were not modeled as individual finite members, but their effects were included in concrete model by introducing confined concrete model. All the beams are loaded by displacement control in the vertical direction. Steel bars are merged into concrete elements (Fig. 2).
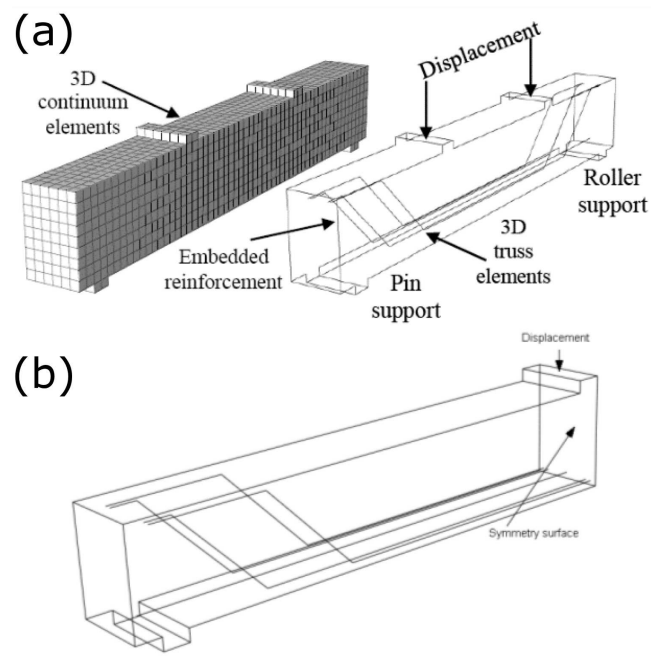

Fig. 2. (a) layout of the beam in verification models; (b) beam used through parametric study.

Stress-strain curve of the concrete under uniaxial compression was obtained by the Hognestad parabola along with linear descending branch and modifications weare made to this parabola according to CEB-FIP MC90 to add the effects of closed stirrups [17]. Bilinear model was adopted for tensile behavior of concrete [18]. Tensile fracture energy of concrete, $\left(G_{F}\right)$, was determined as a function of concrete compressive strength, $f_{c}{ }^{*}$, and a coefficient, $G_{f o}$, which is related to the maximum aggregate size [19]. Concrete damaged plasticity (CDP) model 
combining the effect of both damage and plasticity was used in this study. For CDP two main failure mechanisms are tensile cracking and compressive crushing of the concrete [20]. The detail of the calculation of damage variable in compression and tension for this study can be found in [21]. The regular truss element in ABAQUS was employed for modeling of reinforcing bars. Ideal plasticity model was employed to model the material property of the reinforcing steel [22].

\section{Numerical model validation}

The ability of numerical model addressing the yielding zone of reinforcement bars was the important part of this study. Test specimens constructed with a technique of installing strain gages through the center of the reinforcement, conceived by Mainst in 1952, was selected for this study. Load-displacement relation was important to check, whether the proposed model is coherent or not, by the experimental test as graphically. Three experiments were selected for verification purposes. Details of all experiments used for verification of the numerical models can be found [23], [24] and [25] respectively. Used material properties for all tests are listed in Table I. The verification of results had shown, that proposed numerical modeling approach can successfully represent the experimental results by means of load deflection (Fig. 3a). At the same time the stress distribution at tensile steel for different load levels presented for the test beam named B15 were verified by numerical model in Fig. $3 \mathrm{~b}$. The section, where stress vary rapidly, is believed to be the result of crack propagation, which is not considered in numerical model. Besides that overall pattern of the diagrams agrees well.
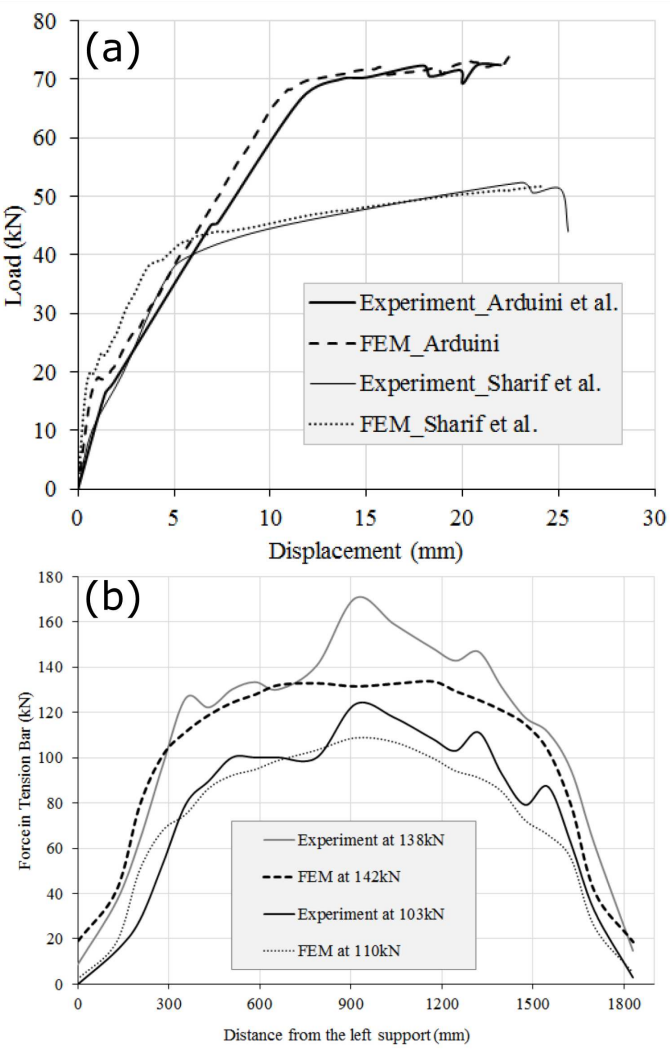

Fig. 3. Numerical model verification results: (a) loaddeflection relationship obtained by using $35^{\circ}$ and $30^{\circ}$ dilation angle, 50 and $25 \mathrm{~mm}$ mesh size, 16 and $8 \mathrm{~mm}$ aggregate size respectively; (b) stresses at tension reinforcement of $\mathrm{RC}$ beam obtained by using $30^{\circ}$ dilation angle, $35 \mathrm{~mm}$ mesh and $16 \mathrm{~mm}$ aggregate size.

Material properties of test beams.

TABLE I

\begin{tabular}{c|c|c|c|c|c|c|c|c}
\hline \hline Test case & Beam No. & $E_{c}[\mathrm{GPa}]$ & $f_{c}[\mathrm{MPa}]$ & $f_{t}[\mathrm{MPa}]$ & $E_{s}[\mathrm{GPa}]$ & $f_{y}[\mathrm{MPa}]$ & $\begin{array}{c}\text { Tension } \\
\text { bars }[\mathrm{mm}]\end{array}$ & $\begin{array}{c}\text { Bent-up } \\
\text { bars }[\mathrm{mm}]\end{array}$ \\
\hline 1 & $\mathrm{~A} 1$ & 25 & 33 & 2.6 & 200 & 540 & $2 \Phi 14$ & - \\
2 & $\mathrm{P} 1$ & 27 & 37.7 & - & 200 & 450 & $2 \Phi 10$ & - \\
3 & $\mathrm{~B} 15$ & 26.8 & 28.8 & 2.84 & 213.7 & 5943 & $1 \times 22.2$ & $4 \times 12.72$
\end{tabular}

All these results show that finite element modeling techniques applied herein, are valid for RC beams. Based on these results, it appears that the present modeling techniques are sufficiently robust for further parametric study to investigate the effects of different parameters on plastic hinge regions of existing $\mathrm{RC}$ beams.

\section{Parametric study}

By using the verified finite element modelling techniques, a parametric study was carried out to investigate the effect of tensile yielding on the $L_{p}$ of reinforced concrete beams, designed to achieve different failure mode (Table II). Half of the beam is modeled with three different lengths to consider the slenderness effect and with three different tension reinforcement steel ratio to consider the ductile behavior. The nomination $\mathrm{C}, \mathrm{T}$ and $\mathrm{F}$ in specimen name indicates the rank of the tension reinforcement ratio in decreasing order as (C)ompression, (T)ransition and (F)lexural, respectively. Other nomination S, I and D represents the slenderness of beam, stating (S)lender, (I)ntermediate and (D)eep as described according to Fig. 1.

Geometry and material properties of test beams are presented in Table III. The beams are loaded by displacement control until they fail. The length of loading span is taken as equal to the shear span, $a$. So the total length of the beam is $3 a$. For the credence of the study, beams reinforcement scheme is applied identical with the Test case- 3 used in the verification study. Cracking pattern of 
Parametric study for numerical beams to achieve different failure modes.

\begin{tabular}{c|c|c|c}
\hline \hline \multirow{2}{*}{ Steel ratio } & \multicolumn{3}{|c}{ Slenderness } \\
\cline { 2 - 4 } & Deep (D) & Intermediate (I) & Slender (S) \\
\hline$\rho_{\text {comp }}(\mathrm{C})$ & Beam CD & Beam CI & Beam CS \\
$\rho_{\text {trans }}(\mathrm{T})$ & Beam TD & Beam TI & Beam TS \\
$\rho_{\text {flexr }}(\mathrm{F})$ & Beam FD & Beam FI & Beam FS
\end{tabular}

the concrete gives information about overall behavior of reinforce concrete. It is obvious that failure of $\mathrm{RC}$ beams in the diagonal of parametric study matrix (Table II) will be controlled by compression transient and flexure for beam CD, TI and FS, respectively. To prove the validity of proposed mechanical and geometrical values used to model different behaviors, crack patterns observed at the initiation of yielding at main tension bar are plotted for these specimens in Fig. 4.

(a)

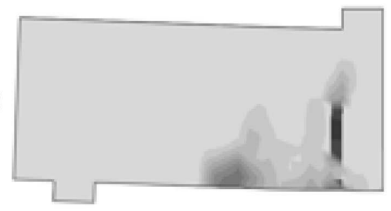

(b)

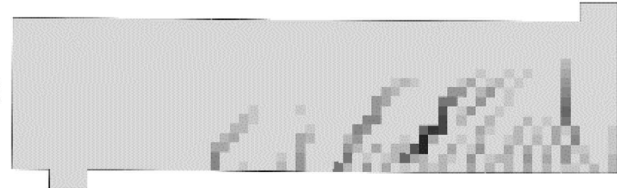

(c)

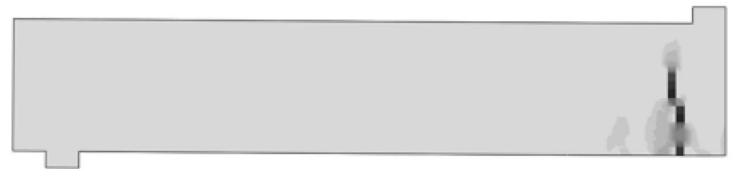

Fig. 4. Cracking pattern of numerical beams with various failure modes: (a) Beam CD $(L=750 \mathrm{~mm})$, (b) Beam TI $(L=1450 \mathrm{~mm})$, (c) Beam FS $(L=$ $2000 \mathrm{~mm}$ ).

Shear cracks dominates the behavior of beam CD at shear span in Fig. 4a. Both shear and flexural cracks can be observed at beam TI in Fig. 4b. Finally, flexural cracks are clearly visible at loading span of beam FS in Fig. 4c. According to these results numerical modelling approaches with parametric values presented herein is able to catch the specified failure behavior of RC beams.

\section{Results and discussions}

After the analysis had been completed stress values of tension bars were investigated closely. Initiation and propagation of yielding for each loading step is checked until ultimate load point is reached. Stress level of tension bar was plotted at ultimate load level to determine the yielding zone of reinforcement. Moreover, cracks at concrete were also plotted for the same load level to address the plastic hinge length. These plots are given in
TABLE III

Mechanical and geometrical variables of numerical beams used in parametric studies $\left(\varepsilon_{t}-\right.$ strain of steel, $\rho$ - reinforcement ratio, $f_{c}=25 \mathrm{MPa}, f_{t}=3 \mathrm{MPa}$, $\left.E_{c}=23.5 \mathrm{GPa}, f_{y}=420 \mathrm{MPa}, E_{s}=210 \mathrm{GPa}\right)$.

\begin{tabular}{c|c|c|c|c|c|c}
\hline \hline $\begin{array}{c}\text { Specimen } \\
\text { name }\end{array}$ & $\varepsilon_{t}$ & $\rho$ & $\begin{array}{c}a \\
{[\mathrm{~mm}]}\end{array}$ & $\begin{array}{c}L \\
{[\mathrm{~mm}]}\end{array}$ & $a / d$ & $L / h$ \\
\hline $\mathrm{CS}$ & $\varepsilon_{t}<0.2 \%$ & 0.026 & 2000 & 6200 & 5.7 & 15.5 \\
$\mathrm{TS}$ & $0.2 \%<\varepsilon_{t}<0.6 \%$ & 0.018 & 2000 & 6200 & 5.7 & 15.5 \\
$\mathrm{FS}$ & $\varepsilon_{t}>0.6 \%$ & 0.014 & 2000 & 6200 & 5.7 & 15.5 \\
$\mathrm{CI}$ & $\varepsilon_{t}<0.2 \%$ & 0.026 & 1400 & 4500 & 4 & 11.25 \\
$\mathrm{TI}$ & $0.2 \%<\varepsilon_{t}<0.6 \%$ & 0.018 & 1400 & 4500 & 4 & 11.25 \\
$\mathrm{FI}$ & $\varepsilon_{t}>0.6 \%$ & 0.014 & 1400 & 4500 & 4 & 11.25 \\
$\mathrm{CD}$ & $\varepsilon_{t}<0.2 \%$ & 0.026 & 700 & 2400 & 2 & 6 \\
$\mathrm{TD}$ & $0.2 \%<\varepsilon_{t}<0.6 \%$ & 0.018 & 700 & 2400 & 2 & 6 \\
$\mathrm{FD}$ & $\varepsilon_{t}>0.6 \%$ & 0.014 & 700 & 2400 & 2 & 6
\end{tabular}

Values of $L_{p}$ for each parametric beam

TABLE IV

\begin{tabular}{c|c|c|c|c|c|c}
\hline \hline \multirow{2}{*}{ Steel ratio } & \multicolumn{6}{|c}{ Slenderness } \\
\cline { 2 - 7 } & \multicolumn{2}{|c|}{ Deep (D) } & \multicolumn{2}{|c}{ Intermediate (I) } & \multicolumn{2}{c}{ Slender (S) } \\
\cline { 2 - 7 } & $L_{p}$ & $L_{p} / d$ & $L_{p}$ & $L_{p} / d$ & $L_{p}$ & $L_{p} / d$ \\
\hline$\rho_{\text {comp }}(\mathrm{C})$ & 372 & 0.99 & 514 & 1.37 & 567 & 1.51 \\
$\rho_{\text {trans }}(\mathrm{T})$ & 315 & 0.84 & 495 & 1.32 & 505 & 1.35 \\
$\rho_{\text {flexr }}(\mathrm{F})$ & 185 & 0.49 & 248 & 0.66 & 357 & 0.95
\end{tabular}

Fig. 5. In particular, results of beams reinforced as compression illustrated in Fig. 5a as their slenderness from top to bottom.

Figure 5b shows the results of beams reinforced as transition also and the Fig. $5 \mathrm{c}$ represents the results of beams reinforced as flexural. Considering the length of yield line of tension bar and concrete cracks, $L_{p}$ is calculated and normalized with the effective depth of the cross section, $d$ (Table IV). For a given steel ratio (herein mentioned as $C, T, F), L_{p} / d$ value increases as the slenderness ratio increases. On the other hand, for a given slenderness value (herein mentioned as $D, I, S), L_{p} / d$ value decreases as the steel ratio decreases. The highest value of $L_{p} / d$ is obtained as 1.51 for slender beam reinforced with steel ratio calculated with compression controlled strain value. The minimum value of $L_{p} / d$ is obtained as 0.49 for deep beam reinforced with steel ratio as tension controlled strain value.

$L_{p} / d$ value is decreased by up to $51 \%$ for the extreme reinforcement values used in this study for compression and tension controlled beam with same shear span. When the extreme slenderness values, deep and slender beams, are compared for a given steel ratio $L_{p} / d$ value is found to be increased by $53 \%, 61 \%$ and $94 \%$ for compression, transition and tension controlled beam, respectively. For the same tensile reinforcement ratio decrease of $L_{p}$ is the result of shear span ratio. All the deep beams have the least $L_{p}$ value while the slender beams have the maximum $L_{p}$ values. The highest value of $L_{p}$ is obtained as $567 \mathrm{~mm}$ for slender beams reinforced with compression controlled strain value. 
(a)
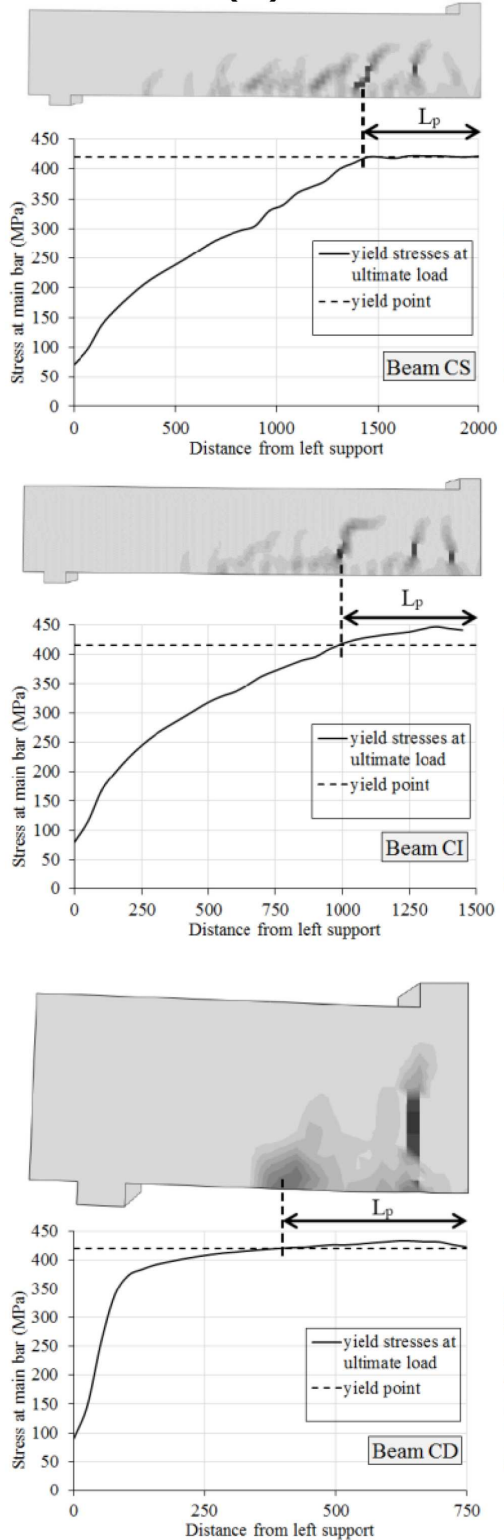

(b)
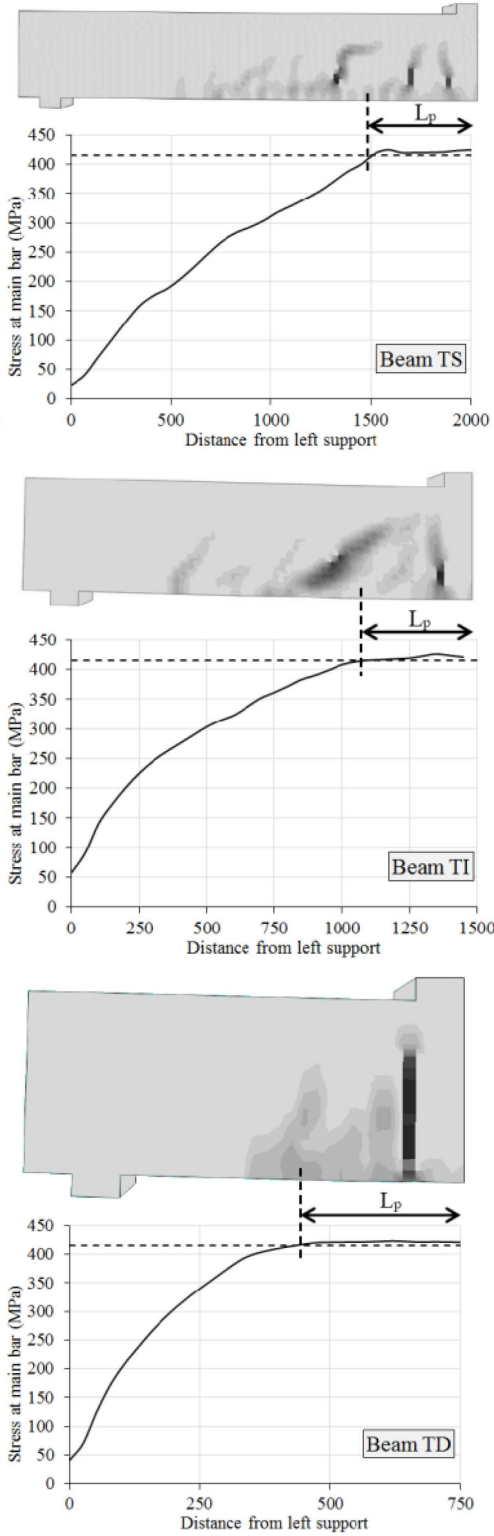

(c)
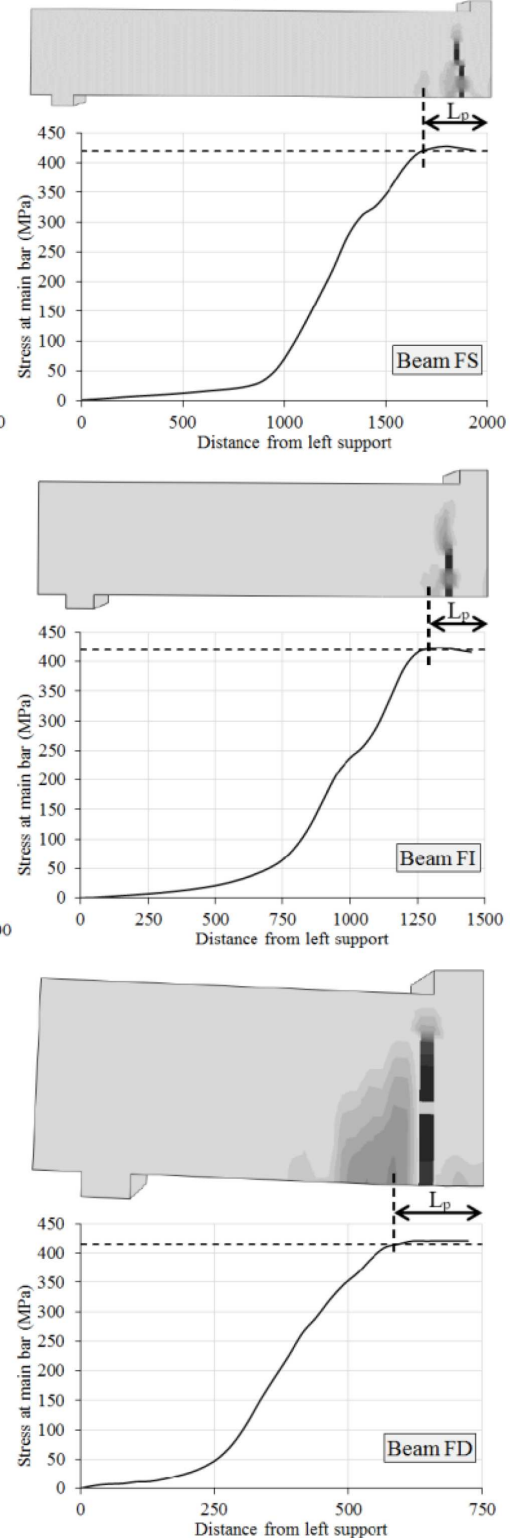

Fig. 5. Determination of $L_{p}$ for each parametric beam: (a) results of beams reinforced as compression, (b) results of beams reinforced as transition, (c) results of beams reinforced as flexural.

Comparison of $L_{p}$ from literature (units are in $\mathrm{mm}$ )

TABLE V

\begin{tabular}{c|c|c|c|c|c|c|c|c|c|c|c|c}
\hline \hline \multirow{2}{*}{ Beam No. } & \multicolumn{2}{|c|}{ FEM } & \multicolumn{2}{|c|}{ Ref. [6] } & \multicolumn{2}{|c|}{ Ref. [2] } & \multicolumn{2}{|c|}{ Ref. [3] } & \multicolumn{2}{|c}{ Ref. [4] } & \multicolumn{2}{c}{ FEMA } \\
Ref. [5]
\end{tabular}


The minimum value of $L_{p}$ is obtained as $185 \mathrm{~mm}$ for deep beams reinforced with tension controlled strain value. As shown in Table IV $L_{p} / d$ values are increased nearly $102 \%$ and $108 \%$ for the deep and intermediate beams as the reinforcement ratio increases through the flexural to compression respectively. It is observed that this increase remained around $59 \%$ for slender beams. Expressions found in the literature for determining the equivalent plastic hinge length (Eqs. (1)-(5)) are used to calculate $L_{p}$ for the parametric numeric beams and normalized values are tabulated in Table $\mathrm{V}$.

In FEMA $L_{p}$ is calculated without considering the failure modes and slenderness of the beam. This is a very conservative approach. It is valid for beams designed with a steel ratio to achieve a tension controlled failure and shear span ratio of 2.5. Corley [2] and Mattock [3] somehow considers the shear span by introducing the point of contraflexure in the expression, but they do not include yielding of the tensile bar. Expression provided in [4] and [5] take the yielding of the tension bar into account along with the point of contraflexure. Thus, different failure modes provide different $L_{p}$ values similar to those obtained from FEM analysis but with far different values. Results obtained from [4] and [5] show the similar tendency with FEM results. All results provide decrease in $L_{p}$ value from slender to deep beam. Thus, effect of shear span ratio which is defined as slender, intermediate and deep is clear. However, there is a big difference in the values from numerical results and existing expressions in compression controlled and transition zone. Author believe that not only the onset of yielding but the yielding length of tension bar should also be considered in the existing expressions. Expressions in [3] were developed by considering monotonic loading, however the others were developed considering cyclic loading. One interesting outcome of the results seen in Fig. 5 is, that expressions considering cyclic loading define plastic hinge length shorter only for deep beams.

\section{Conclusion}

In this numerically verified study RC beams with different failure modes were created by considering both tension reinforcement ratio and span to depth ratio. Then plastic hinge length for these beams were determined and compared with the existing equation results. Findings can be summarized as follows:

1. finite element approach is capable of capturing load-deflection relationship and stresses developed in the steel bar embedded in concrete;

2. $L_{p}$ is correlated with the behavior type of beam. It can be tension controlled, compression controlled or transient;

3. $L_{p}$ is also correlated with the shear span to depth ratio value also, which is named as slender, deep and intermediate beam in this study;

4. two expressions in the literature give similar results for tension controlled beams regardless of slenderness ratio;
5. the existing expressions in the literature are very conservative for beams which are designed in compression controlled and transition zone.

\section{References}

[1] R.C. Fenwick, C.W. Thom, Shear deformation in reinforced concrete beams subjected to inelastic cyclic loading, University of Auckland, School of Engineering Report, No. 279, 1982.

[2] G.W. Corley, ASCE J. Struct. Div. 92, 121 (1966).

[3] A.H. Mattock, ASCE J. Struct. Div. 93, 519 (1967).

[4] M.J.N. Priestley, R. Park, ACI Struct. J. 84, 61 (1987).

[5] T.B. Panagiotakos, M.N. Fardis, ACI Struct. J. 98, 135 (2001).

[6] FEMA 356 Prestandart and Commentary for the Seismic Rehabilitation of Buildings, Federal Emergency Management Agency, Washington DC 2000.

[7] R. Park, T. Paulay, Reinforced Concrete Structures, John Wiley \& Sons, New York 1975.

[8] A.W. Beeby, Struct. Eng. 75, 311 (1997).

[9] J.C.M. Ho, Ph.D. thesis, University of Hong Kong, China 2003.

[10] M.P. Berry, Ph.D. thesis, University of Washington, USA 2006

[11] S.J. Bae, O. Bayrak, ACI Struct. J. 105, 290 (2008).

[12] D.S. Gu, Y.F. Wu, G. Wu, Z.S. Wu, Constr. Build. Mat. 27, 223 (2012).

[13] American Concrete Institute (ACI), ACI 318-14: Building Code Requirements for Structural Concrete, ACI, Detroit (MI) 2014.

[14] J.K. Wight, J.G. Macgregor, Reinforced Concrete Mechanics and Design, 5th ed., 2012.

[15] T. Potisuk, C.C. Higgins, T.H. Miller, S.C. Yim, Adv. Civil Eng. 2011, 706803 (2011).

[16] E. Agcakoca, M. Aktas, Math. Probl. Eng. 2012 , 183906 (2012).

[17] M. Arduini, A. Nanni, J. Struct. Eng. ASCE 1, 63 (1997).

[18] A.C. Coronado, M.M. Lopez, Cement Concr. Comp. 28, 102 (2006).

[19] CEB-FIP MC90, CEB-FIP Model Code 1990, Bulletin d'Information, Comite Euro-International du Beton, Lausanne 1993, No. 215.

[20] Abaqus/CAE, User's Guide, Ver. 6.13, Dassault Systèmes Simulia, Providence (RI) 2014.

[21] Y. Sümer, APJES 5, 39 (2017) (in Turkish).

[22] M. Aktas, C.J. Earls, J. Struct. Eng. ASCE 32, 1079 (2006).

[23] M.D.T. Arduini, A. Nanni, ACI Struct. J. 94, 363 (1997).

[24] A. Sharif, G.J. Al-Sulaimani, I.A. Basunbul, M.H. Baluch, B.N. Ghaleb, ACI Struct. J. 91, 160 (1994).

[25] R.M. Mains, J. Am. Concr. Inst. Proc. 48, 225 (1951). 